\title{
Physicians' Views of Self-Monitoring of Blood Glucose in Patients With Type 2 Diabetes Not on Insulin
}

\author{
Sonia A. Havele \\ Elizabeth R. Pfob, PbD, MPH ${ }^{2}$ \\ Chen Yan, $M D^{3}$ \\ Anita D. Misra-Hebert, MD, MPH', \\ Pbuc Le, PbD, MPH ${ }^{2}$ \\ Michael B. Rotbberg, MD, MPH \\ ${ }^{1}$ Case Western Reserve University School \\ of Medicine, Cleveland, Ohio \\ ${ }^{2}$ Center for Value-Based Care Research, \\ Cleveland Clinic, Cleveland, Ohio \\ ${ }^{3}$ Department of Neurology, Cleveland \\ Clinic, Cleveland, Ohio \\ ${ }^{4}$ Department of Quantitative Health \\ Sciences, Cleveland Clinic, Cleveland, \\ Ohio
}

Conflicts of interest: authors report none.

\section{CORRESPONDING AUTHOR:}

Sonia Havele

Cleveland Clinic Medicine Institute 9500 Euclid Avenue

Cleveland, $\mathrm{OH} 44195$

Sah182@case.edu

\begin{abstract}
This qualitative study examines to what extent and why physicans still prescribe self-monitoring of blood glucose (SMBG) in patients with non-insulin-treated type 2 diabetes (NITT2D) when the evidence shows it increases cost without improving hemoglobin $A_{1 c}\left(\mathrm{HbA}_{1 \mathrm{c}}\right)$, general well being, or health-related quality of life. Semistructured phone interviews with 17 primary care physicians indicated that the majority continue to recommend routine self-monitoring of blood glucose due to a compelling belief in its ability to promote the lifestyle changes needed for glycemic control. Targeting physician beliefs about the effectiveness of self-monitoring of blood glucose, and designing robust interventions accordingly, may help reduce this practice.
\end{abstract}

Ann Fam Med 2018;16:349-352. https://doi.org/10.1370/afm.2244.

\section{INTRODUCTION}

E vidence on self-monitoring of blood glucose (SMBG) in patients with non-insulin-treated type 2 diabetes (NITT2D) shows that routine testing increases cost ${ }^{1}$ without improving glycemic control, general well-being, or health-related quality of life. ${ }^{2,3}$ Self-monitoring of blood glucose can be painful, inconvenient, and depressing. ${ }^{4}$ The Society of General Internal Medicine advises against daily glucose testing, ${ }^{5}$ yet the American Diabetes Association recommends it. ${ }^{6}$ Proponents of daily glucose monitoring argue that it improves glycemic control, distress, and self-efficacy when used in a targeted manner. ${ }^{7}$ Examining to what extent and why physicians continue to recommend SMBG is essential for understanding how this debate permeates care. Thus, we undertook this qualitative study.

\section{METHODS}

From December 2016 to June 2017, semistructured interviews were conducted with full-time ( $>0.8$ FTE) Cleveland Clinical Internal Medicine (IM) and Family Medicine (FM) physicians in Ohio. Eligible physicians from 25 sites were randomly ordered and sequentially e-mailed invitations to participate. Phone interviews were conducted in order of response and ceased when thematic saturation was reached.

The interview guide was based on the Health Belief Model, a literature review, and advice from a panel of diabetes experts. Questions were grouped into sections: beliefs about SMBG, recommendations, and use during clinical encounters. Two team members (S.H. and E.P.) conducted and analyzed all interviews. Interviews were audio-recorded and transcribed. Transcripts were iteratively coded to capture themes. Physicians were categorized as proponents or opponents based on whether they recommended routine SMBG to most patients with NITT2D. Proponents were further categorized as continual proponents (ie, long-term, routine testing for all) or limited proponents (ie, routine checking for newly diagnosed and/or uncontrolled type 2 diabetes). 


\section{RESULTS}

Seventeen physicians from 10 sites participated. Five were female and 12 were male. Ten were FM and 7 were IM. In total, there were 14 proponents: 8 continual proponents and 6 limited proponents (Table 1). There were small differences in the breakdown of proponents and opponents when comparing FM to IM physicians (continual proponents: $40 \%$ FM [4] vs $71 \%$ IM [5]; limited proponents $40 \%$ FM [4] vs $14 \%$ IM [1]; opponents: $20 \%$ FM [2] vs $14 \%$ in IM [1]).

There were 4 major themes identified. Overall, proponents believed SMBG plays a significant role in education and lifestyle change, resulting in better glycemic control. Opponents were concerned about lack of efficacy in lowering hemoglobin $\mathrm{A}_{1 \mathrm{c}}\left(\mathrm{HbA}_{1 \mathrm{c}}\right)$, and more often cited evidence (2/3) than proponents (4/14). Physician perspectives for each theme are summarized below and additional quotations are provided in Table 2.

\section{Theme 1. Education for Lifestyle Change}

\section{Patient Activation}

The majority of proponents believed SMBG works best at initial diagnosis, facilitating education and selfmanagement. "If someone is educated on a behavior or therapy and follows through, and they can see...the benefit of that sugar coming down... that causes a feedback loop that is amazing" (Physician 16).

Opponents believed in-office education alone encourages patient activation and cited evidence that
SMBG does not improve patient outcomes "...the net analysis has not shown any direct impact [of SMBG] on $[\mathrm{Hb}] \mathrm{A}_{1 \mathrm{c}}$ or other outcomes" (10).

\section{Patient-Centered Care}

Proponents reported tailored negotiations about daily choices based on SMBG readings. "I had a patient who was drinking five beers a night, so his sugars were $300 \ldots$ we negotiated to cut back on the alcoholmaybe switch to vodka and a diet sprite or do two versus the five beers. It's a lesser of two evils" (5).

Opponents felt $\mathrm{HbA}_{1 \mathrm{c}}$ sufficiently fosters patientcentered care. "We look at the most recent $\left[\mathrm{HbA}_{1 \mathrm{c}}\right] \ldots$ and talk with the patient about shared decision making if changes are suggested, based on the $[\mathrm{Hb}] \mathrm{A}_{1 \mathrm{c}}$ being too low or too high" (10).

\section{Theme 2. Value-Based Care}

All physicians agreed $\mathrm{HbA}_{1 \mathrm{c}}$ surpasses $\mathrm{SMBG}$ when making medication choices. "I make way more treatment and management decisions based on $[\mathrm{Hb}] \mathrm{A}_{1 \mathrm{c}}$ than I do based on home glucose monitoring, because $\left[\mathrm{HbA}_{1 \mathrm{c}}\right]$ is more of a trend than an isolated data point" (7).

\section{Affordability for Patients}

Proponents and opponents cited cost as a major barrier to SMBG adherence. "Strips cost anywhere between 50 cents or more per day... that could turn out to be the cost of another medication" (13). Physicians practicing in lower-income populations cited this concern more often.

\section{Table 1. Summary of Physician Perspectives on SMBG in Non-Insulin-Treated Type 2 Diabetes}

\begin{tabular}{|c|c|c|c|}
\hline & Continual Proponents & Limited Proponents & Opponents \\
\hline $\begin{array}{l}\text { Beliefs on rec- } \\
\text { ommendation } \\
\text { of SMBG }\end{array}$ & $\begin{array}{l}\text { "It allows for, first, assessment of } \\
\text { hypo- or hyperglycemia. Two, it } \\
\text { reinforces patient behavior as it } \\
\text { relates to nutrition, exercise, and } \\
\text { diet. Three, it allows for appropri- } \\
\text { ate medication adjustments... Four, } \\
\text { if there is any sudden change in } \\
\text { their glucose, their glucose sta- } \\
\text { tus allows for us to intervene in } \\
\text { between office visits" (15). }\end{array}$ & $\begin{array}{l}\text { "I think self-monitoring is helpful for } \\
\text { patients who have uncontrolled } \\
\text { blood sugars to move them in the } \\
\text { direction of getting their blood } \\
\text { sugars under control, with thera- } \\
\text { peutic interventions such as diet, } \\
\text { exercise, and medications" (12). }\end{array}$ & $\begin{array}{l}\text { "I will tell them, 'Based on recent evidence, } \\
\text { there is no indication that you have to } \\
\text { check your sugar to control your diabe- } \\
\text { tes, because we are checking the three- } \\
\text { month blood level. I think it's okay, and I } \\
\text { feel safe with you not doing this as long } \\
\text { as you're comfortable'" (5). }\end{array}$ \\
\hline $\begin{array}{l}\text { Frequency of } \\
\text { prescribing } \\
\text { SMBG }\end{array}$ & $\begin{array}{l}\text { "[l advise checking] twice a day, } \\
\text { morning and evening. Some } \\
\text { people, if they are very well con- } \\
\text { trolled, I will say, 'You know what. } \\
\text { Why don't you check every other } \\
\text { day'" (5). }\end{array}$ & $\begin{array}{l}\text { "I recommend that all sugars be } \\
\text { done at fasting, first thing in the } \\
\text { morning [initially]. After we get to } \\
\text { a point where they are stable and } \\
\text { we are not recommending daily } \\
\text { sugar checks, I will recommend } \\
\text { they check their sugars [only] if } \\
\text { they are feeling sick...nauseous, or } \\
\text { light-headed" (1). }\end{array}$ & $\begin{array}{l}\text { "I try to steer non-insulin dependent } \\
\text { patients away from testing at home, } \\
\text { mainly because it doesn't change what I } \\
\text { do. I monitor their diabetes based on the } \\
\mathrm{HbA}_{1 \mathrm{c}} \text { and occasional sugar checks" (6). }\end{array}$ \\
\hline $\begin{array}{l}\text { Beliefs on stop- } \\
\text { ping SMBG }\end{array}$ & $\begin{array}{l}\text { "I never recommend that they stop } \\
\text { completely" (3). }\end{array}$ & $\begin{array}{l}\text { "If they know what foods to eat... } \\
\text { and their } \mathrm{HbA}_{1 \mathrm{c}} \text { is under great } \\
\text { control, then there is really no } \\
\text { reason for them to check their } \\
\text { blood sugars" (17). }\end{array}$ & $\begin{array}{l}\text { "I don't tend to ever start [SMBG] in some- } \\
\text { one who is just on orals. Many times I } \\
\text { am inheriting patients who are already } \\
\text { on it and used to it, so I encourage them } \\
\text { to stop. But, they don't necessarily want } \\
\text { to stop" (10). }\end{array}$ \\
\hline
\end{tabular}




\section{Health Care System Costs}

A few proponents argued that engaging patients with SMBG could reduce expensive complications. "The most important way for us to manage the everincreasing cost of care in this country is to engage our patients to be part of the solution in managing their health" (16).

Opponents expressed concern about SMBG's contribution to health care spending and limited impact on treatment decisions. "Routine testing-I bet there are millions of dollars we are wasting" (6).

\section{Theme 3: Patient Safety}

Proponents and opponents frequently cited hypoglycemia as a reason to prescribe SMBG. "If they are ... at risk for hypoglycemia, and if I am concerned they are at risk for silent or asymptomatic hypoglycemia, that's where testing can be helpful" (15)

\section{Theme 4. Considerations for Specific Patient Populations}

Both groups identified populations (eg, patients with physical or cognitive disability) who were nonideal candidates for SMBG "[For] patients with rheumatoid arthritis, it would be quite challenging to do finger sticks" (13). Physicians modified SMBG use among patients with low socioeconomic status, who face adherence barriers including poor health literacy. One proponent said: "I'm...less stringent about their [SMBG] requirements, because it's just going to be

Table 2. Additional Physician Perspectives Related to Major Themes

Proponents
Theme 1. Education for Lifestyle Change
Patient Activation
"Over and over again, I have noticed that people who check their blood
sugar tend to be more engaged in the self-management of their diabe-
tes" (14).
Patient-Centered Care
"If I have somebody who is pretty much in the action phase of wanting
to control their disease and their blood sugar is in the >9 category, I
would be more aggressive with them checking and trying to manipu-
late the diet. But I'm very patient-centered, so I would ask them, 'On
a scale from 1-10, how important is it for you to check your blood
sugar?' If they say it's $7-8$ or 9,1 would say, 'Okay, what is your ideal
state of checking a blood sugar.' Then, I would see what they would
say and do a confidence scale, 'On a scale from 1 -10, how confident are
you that you can check your blood sugar?' Let's say they say 4 times a
week. If I can get them above a 7, then I would go for it" (4).

Opponents

\section{Theme 2. Value-Based Care}

\section{Affordability for Patients}

"I take into account that I know these strips are very expensive, and for many patients, that's a barrier. So I may tell them to check just once a day but at different times during the day" (13)

\section{Health Care System Costs}

"It helps to give us more short-term strategies to fix things rather than waiting for a three-month follow-up, when things can get ahead of us too far" (12).

\section{Theme 3. Patient Safety}

"If a person is having symptoms that suggest hypoglycemia, then I would use [SMBG]. If we were able to actually avoid the hypoglycemia, then we can avoid potential cognitive damage or an injury related to hypoglycemia, like loss of consciousness and a fall" (8).

\section{Theme 4. Considerations for Specific Patient Populations}

"For a patient in their eighties who may have some cognitive disability, measuring their blood sugars every day or a couple of times a week, especially if they are doing well, may not really be very useful" (13).
"I tend to see the patients who keep monitoring are the ones who are generally more engaged around their self-care..... In my experience, [SMBG] has been mostly correlated with their level of activation rather than the disease" (10)

"Usually, they are a bit hesitant [to stopping SMBG]...50\% of patients don't want to stop checking, because they are so used to it, so I will let them continue it. I won't force them to stop" (5).

"This sounds painful and possibly expensive, you should stop and save your blood" (10).

"For those patients not on insulin, I think we are probably wasting a lot of money. We are doing tons of testing unnecessarily" (5).

"I talk about a constellation of symptoms and when they might expect to feel those. It's usually within a few hours of taking certain medicine or on days when they notice that they are skipping meals or that they are very sick from the cold. We talk a little bit about the general feeling of dizziness, lethargy, sweating, hunger, disorientation, and try to educate both the patient and whoever might be around them that these are signs or symptoms to look out for-to focus first on the intervention, which is go eat or drink something, but then also to check their blood sugar if they have time" (10).

"Some patients really need to see that number at certain times of the day, because it helps them become motivated to bring it down. Other ones, though, it's the complete opposite. It interferes with their care, because they see it and they don't understand" (6). 
a difficult situation trying to figure out how they're going to get their glucometer to work" (3).

\section{DISCUSSION}

The majority of physicians still recommend routine SMBG because they believe it drives the lifestyle changes needed for improved glycemic control. This view may be rooted in strong memories of patients who successfully modified their habits. The fact that the American Diabetes Association recommends SMBG based on expert opinion may further reinforce beliefs that SMBG facilitates change. Opponents often cited peer-reviewed evidence as a reason not to prescribe SMBG. Training background (family vs internal medicine) did not strongly affect SMBG viewpoints. Limitations include physicians from a single institution, minimal participant demographic information, and exclusion of nonphysician providers.

Health care systems can look to SMBG as an opportunity to reduce spending with little to no harm to patients. ${ }^{8}$ Given that educational outreach alone has small benefits in changing behavior, ${ }^{9}$ targeting physicians' beliefs about the effectiveness of SMBG, along with policy-based interventions, ${ }_{1}^{10}$ could reduce this practice.

To read or post commentaries in response to this article, see it online at http://www.AnnFamMed.org/content/16/4/349.

Key words: Self-monitoring of blood glucose (SMBG); glucose monitoring; home monitoring; glucometer; test strips; non-insulin-treated type 2 diabetes; insulin naïve diabetes; $\mathrm{HbA}_{1 c}$; evidence-based medicine

Submitted September 14, 2017; submitted, revised, January 25, 2018; accepted February 19, 2018.

Funding support: Dr Misra-Hebert receives funding from the Agency for Healthcare Research and Quality (K08HS024128) and has received grant funding from the Merck Investigators Studies Program and Novo Nordisk in the past 12 months unrelated to this manuscript. No funder had any role in the design and conduct of the study; collection, management, analysis, and interpretation of the data; preparation, review, or approval of the manuscript; or decision to submit the manuscript for publication.

Previous presentation: An abstract of this study was presented at the Society of General Internal Medicine Midwest Regional Meeting; September 14, 2017; Chicago, Illinois.
Acknowledgments: Data access, responsibility and analysis: S.H. had full access to all the data in the study and takes responsibility for the integrity of the data and accuracy of the data analysis. M.R. and C.Y. conceived and designed the initial concept. S.H. and E.P. undertook the acquisition, analysis, and interpretation of the data, as well as the writing of the manuscript. All authors contributed to critical revisions of the manuscript for important intellectual content. Additionally, we thank the physicians who took the time to share their thoughts on SMBG, and Sarah Schramm for her administrative support.

\section{References}

1. Clar C, Barnard K, Cummins E, Royle P, Waugh N; Aberdeen Health Technology Assessment Group. Self-monitoring of blood glucose in type 2 diabetes: systematic review. Health Technol Assess. 2010; 14(12):1-140.

2. Malanda UL, Welschen LM, Riphagen II, Dekker JM, Nijpels G, Bot SD. Self-monitoring of blood glucose in patients with type 2 diabetes mellitus who are not using insulin. Cochrane Database of Syst Rev. 2012;(1):CD005060.

3. Young LA, Buse JB, Weaver MA, et al; Monitor Trial Group. Glucose self-monitoring in non-insulin-treated patients with type 2 diabetes in primary care settings: a randomized trial. JAMA Intern Med. 2017; 177(7):920-929.

4. O'Kane MJ, Bunting B, Copeland M, Coates VE; ESMON study group. Efficacy of self monitoring of blood glucose in patients with newly diagnosed type 2 diabetes (ESMON study): randomised controlled trial. BMJ. 2008;336(7654):1174-1177.

5. Society of General Internal Medicine. Daily home finger glucose testing; choosing wisely. http://www.choosingwisely.org/clinicianlists/society-general-internal-medicine-daily-home-finger-glucosetesting-type-2-diabetes-mellitus/. Published Sep 12, 2013. Updated Feb 15, 2017. Accessed Jun 21, 2017

6. American Diabetes Association. Standards of Medical Care in Diabetes-2017. Diabetes Care. 2017;40(Suppl 1):S1-S2. https:// professional.diabetes.org/sites/professional.diabetes.org/files/media/ dc_40_s1_final.pdf. Published Jan 1017. Accessed Jun 22, 2017.

7. Polonsky WH, Fisher L. Self-monitoring of blood glucose in noninsulin-using type 2 diabetic patients: right answer, but wrong question: self-monitoring of blood glucose can be clinically valuable for noninsulin users. Diabetes Care. 2013;36(1):179-182.

8. Gomes T, Martins D, Tadrous M, et al. Self-Monitoring of blood glucose levels: evaluating the impact of a policy of quantity limits on test-strip use and costs. Can J Diabetes. 2016;40(5):431-435.

9. O’Brien MA, Rogers S, Jamtvedt G, et al. Educational outreach visits: effects on professional practice and health care outcomes. Cochrane Database of Syst Rev. 2007;(4):CD000409.

10. Robson J, Smithers H, Chowdhury T, et al. Reduction in selfmonitoring of blood glucose in type 2 diabetes: an observational controlled study in east London. Br J Gen Pract. 2015;65(633): e256-e263. 